\title{
Two Different Integration Methods for Weather Radar-Based Quantitative Precipitation Estimation
}

\author{
Jing Ren, ${ }^{1,2,3}$ Yong Huang, ${ }^{1,3}$ Li Guan, ${ }^{2}$ and Jie Zhou ${ }^{1,2,3}$ \\ ${ }^{1}$ Key Laboratory of Atmospheric Sciences and Satellite Remote Sensing of Anhui Province, Anhui Meteorology Institute, \\ Hefei 230031, China \\ ${ }^{2}$ Nanjing University of Information Science \& Technology, Nanjing 210044, China \\ ${ }^{3}$ Shouxian Climatology Observatory, Shouxian 232200, China \\ Correspondence should be addressed to Yong Huang; hy121_2000@126.com
}

Received 17 November 2016; Revised 19 January 2017; Accepted 20 March 2017; Published 11 April 2017

Academic Editor: Roberto Fraile

Copyright (C) 2017 Jing Ren et al. This is an open access article distributed under the Creative Commons Attribution License, which permits unrestricted use, distribution, and reproduction in any medium, provided the original work is properly cited.

\begin{abstract}
We discuss two different integration methods for radar-based quantitative precipitation estimation (QPE): the echo intensity integral and the rain intensity integral. Theoretical analyses and simulations were used to test differences between these two methods. Cumulative rainfall calculated by the echo intensity integral is usually greater than that from rain intensity integral. The difference of calculated precipitation using these two methods is generally smaller for stable precipitation systems and larger for unstable precipitation systems. If the echo intensity signal is sinusoidal, the discrepancy between the two methods is most significant. For stratiform and convective precipitation, the normalized error ranges from -0.138 to -0.15 and from -0.11 to -0.122 , respectively. If the echo intensity signal is linear, the normalized error ranges from 0 to -0.13 and from 0 to -0.11 , respectively. If the echo intensity signal is exponential, the normalized error ranges from 0 to -0.35 and from 0 to -0.30 , respectively. When both the integration scheme and real radar data were used to estimate cumulative precipitation for one day, their spatial distributions were similar.
\end{abstract}

\section{Introduction}

Weather radar is an effective tool for precipitation estimation and it can provide useful regional flood forecasts. In many studies, weather radar has been used for quantitative precipitation estimates [1-3] and also to develop monitoring techniques [4-7] and integrated applications of multiple estimation methods that are combined with rain gauge data $[8,9]$.

Radar was first used for quantitative precipitation estimation in the late 1940s. Mershall et al. [10] introduced a formula for calculating rainfall intensity $(I)$ from the radar reflectivity factor $(Z)$ termed the $Z-I$ model. Byers and Braham [11] found a strong correlation between the volume of a convective storm and the amount of precipitation. For the radar echo beyond a threshold, the average rainfall intensity is closely related to the radar echo. Several methods for estimating precipitation were introduced later, including the
Brandes objective analysis method [12], regional calibration method [13], the Vertical Profiles of Reflectivity (VPR) method [14], and the Mean Vertical Profiles of Reflectivity (MVPR) method [15].

Precipitation estimation has been improved using new methods such as a combination of satellite-based precipitation products [16-19], merging radar and satellite precipitation [20], machine learning [18, 21], the fusion of multiple radar-based precipitation products method [22], probabilistic quantitative precipitation estimation (PQPE) [23, 24], and the Climatological Vertical Profiles of Reflectivity Identification and Enhancement (CVPR-IE) method [25]. On the basis of Meteosat Second Generation (MSG) and Tropical Rainfall Measuring Mission (TRMM) data, Ouallouche and Ameur [18] used an artificial neural network (ANN) for modelling and presented a new method to delineate rain areas in Algeria. Their approach worked well and overcame the shortcomings of the scattering index (SI) method. Lee et al. [20] 
proposed a method based on the optimal weights needed to fill the radar gap using surrounding radar estimated precipitation and observations from the COMS satellite. This method was tested for major precipitation events during the summer of 2011 with assumed radar gap areas. The results suggested that successful merging appears to be closely related to the quality of the satellite precipitation estimates. Rafieeinasab et al. [22] evaluated four procedures for fusing QPEs of different resolutions based on Fisher estimation and its conditional bias-penalized variant. They searched for a fusion algorithm that can be implemented as a postprocessor to the QPE operation in which multiple gridded QPE products are processed. Their approach was successful in improving the accuracy of high-resolution QPE. Kirstetter et al. [24] used WSR-88D radar data and rain gauge observations to develop a model that quantitatively describes the relationship between radar reflectivity and observed precipitation. They calculated the probability distributions of precipitation rates instead of the deterministic values. This approach reduced the uncertainty structure of radar quantitative precipitation estimation (QPE) at very fine spatiotemporal scales. Based on VPR-IE (vertical profile of reflectivity identification and enhancement) method, Wen et al. [25] obtained climatological VPRs for different seasons, rain types, and rain intensities from 11 years of Tropical Rainfall Measuring Mission (TRMM) Precipitation Radar (PR) data. When these climatological VPRs are used, the TRMM PR products are integrated into the ground-based rainfall estimation system in real time and the precipitation estimate can be significantly improved.

The $Z-I$ relation [26-28] remains one of the most widely used methods for quantitative precipitation estimation. According to the $Z-I$ relation formula, two different integration orders can be adopted to calculate cumulative precipitation. However, due to the nonlinear relationship between the variables, the results from two different integration orders are different. One approach is to first carry out the rainfall intensity conversion through the $Z$ - $I$ relationship, then the rainfall intensity is integrated to obtain the total rainfall (termed the rainfall intensity integral). This is the most widely used method for quantitative precipitation estimation using the $Z$ to $I$ conversion [26-28]. Another approach is to first obtain the distribution of the radar reflectivity factor, integrate the radar reflectivity factor, and finally convert the integral radar reflectivity factor to the precipitation intensity (termed the echo intensity integral). Based on theoretical analysis and simulation studies, we discuss the differences as well as the advantages and disadvantages of each method. The results will help improve the accuracy of precipitation estimation.

\section{Fundamental Principles}

The scattering of radar electromagnetic waves by precipitation particles is the basis for radar detection of precipitation. After radar sends out a signal, the information returned is closely related to the backscattering coefficient of precipitation particles. The weather radar measurement is the sum of the backscatter power of precipitation particles within the effective radiation volume. The echo intensity, denoted as $\mathrm{dB} Z$, represents the magnitude of the echo power, and it is defined as

$$
\mathrm{dB} Z=10 \lg Z
$$

where $Z(\mathrm{~dB})$ is the radar reflectivity factor, and it is defined as

$$
Z=\int_{0}^{\infty} n(D) D^{6} d D
$$

When the vertical airflow near the ground is ignored, the precipitation intensity, denoted as $I(\mathrm{~mm} / \mathrm{h})$, can be calculated from the following formula:

$$
I=\int_{0}^{\infty} n(D) M(D) v(D) d D .
$$

In this formula, $D$ is the diameter of raindrops, $n(D)$ is the number of raindrops per unit volume, $n(D) d D$ represents the number of particles per unit volume of the raindrops whose diameter ranges between $D$ and $D+d D$, and $M(D)$ and $v(D)$ indicate the mass and the terminal falling velocity of raindrops with a diameter of $D$, respectively.

The definitions of the radar reflectivity factor $(Z)$ and precipitation intensity $(I)$ show that they have close relationships with the raindrop size distribution spectrum. The raindrop spectrum characteristics reflect the particle size and the corresponding particle number concentration. $Z$ is proportional to the sixth power of the drop diameter $(D)$ and its number, so the reflectivity factor can be calculated by the raindrop spectrum data. Wu et al. studied raindrop influence of spectrum change on precipitation estimation and found that the echo intensity of radar observation is usually less than the echo intensity calculated from the Ground Raindrop spectrometer. The farther away from the ground, the greater the underestimation of radar echo [28].

Because the raindrop size distribution varies with time and space, especially with different types of precipitation $[29,30]$, the $Z-I$ relation can only be derived theoretically using several assumptions. The current widely used $Z-I$ relation is $Z=a I^{b}$. Radar detection of convective cloud precipitation is characterized by strong reflectivity and a large horizontal reflectivity gradient. When radar is used to detect stratiform cloud precipitation, it is mainly characterized by a relatively weak reflectivity factor and a fairly small horizontal reflectivity gradient. For different precipitation types, the corresponding relation can be obtained from a statistical model with a large amount of raindrop distribution data as input [31]. For example, according to statistical analysis of United States summer convective precipitation, Mueller and Sims [32] found a quantitative relationship between the radar reflectivity factor $Z$ and precipitation intensity I. The $Z$ to $I$ conversion derived by Gerrish and Hiser [33] used the average value of the coefficient and index to obtain a $Z-I$ model of convective precipitation: $Z=$ $300 I^{1.4}$. Marshall and Palmer [34] deduced the stratiform precipitation $Z-I$ relationship using a classical exponential raindrop size distribution (M-P distribution): $Z=200 I^{1.6}$. 
Using the change of radar echo intensity over time, we divided precipitation into stable and unstable precipitation components. If, during a set time period, the echo intensity does not change abruptly, there is no significant change in its maximum, and the waveform remains the same, then it is a stable precipitation. If, during a set time period, the echo intensity abruptly changes, there is a clear change in its maximum, and the waveform undulates; it is an unstable precipitation.

For the total amount of precipitation during a period of time $(T)$, two independent methods can be used to obtain the estimate. One method initially estimates the precipitation intensity $I(t)$ based on the radar reflectivity factor $Z(t)$ obtained from the radar detection and then integrates the estimated precipitation intensity over the period for the total rainfall amount. It is the most widely used method for quantitative precipitation estimation using $Z$ to $I$ conversion. Because it first estimates the instantaneous precipitation intensity and then integrates the total rainfall intensity according to the rainfall intensity, this method is called rain intensity integral, (RI), and the formula is shown as follows:

$$
\mathrm{RI}_{T}=\int_{T} I(t) d t=\int_{T} \sqrt[b]{\frac{Z(t)}{a}} d t
$$

In this formula, $a$ and $b$ are the coefficient and index of $Z$ to $I$ conversion $\left(Z=a I^{b}\right)$, respectively.

From formula (2), we see that the radar reflectivity factor $(Z)$ is proportional to the sixth power of the drop diameter $(D)$, and the greatest contribution comes from large particles. The radar reflectivity factor contains information on the size and quantity of precipitation particles. The other method first obtains the distribution of radar reflectivity factor $(Z)$ and then integrates the radar reflectivity factor $Z(t)$ over a period of time $(T)$. It then converts the integral radar reflectivity factor to the precipitation intensity. This method is termed the echo intensity integral (EI), and the formula is as follows:

$$
\mathrm{EI}_{T}=\sqrt[b]{\frac{Z_{\text {Total }}}{a}}=\sqrt[b]{\frac{\int_{T} Z(t) d t}{a}}
$$

There are two ways to calculate the total precipitation over a region (with $S$ radar detection units in the area) and these are similar to calculating the total rainfall amount over a period of time. $Z(x)$ represents the echo intensity of detection unit $x$

$$
\begin{aligned}
& \mathrm{RI}_{S}=\int_{S} \sqrt[b]{\frac{Z(x)}{a} d x} \\
& \mathrm{EI}_{S}=\sqrt[b]{\frac{\int_{S} Z(x) d x}{a}} .
\end{aligned}
$$

Formulas (4)-(7) all indicate the relationships between cumulative rainfall and the radar reflectivity factor $Z$. In formulas (5) and (7), the echo intensity is first integrated to obtain raindrop spectrum distribution, and then the cumulative rainfall is calculated through the $Z-I$ relation. In formulas (4) and (6), the instantaneous rainfall intensity is first calculated according to the $Z-I$ relation, and then the rainfall intensity is integrated to obtain cumulative rainfall. Because the relationship between $Z$ and $I$ is nonlinear, the results of the two methods are different when $Z$ changes with time. The differences between the two methods for calculating the cumulative rainfall are discussed in the following.

\section{Discussion of Different Integration Methods}

After discretizing the integrals in formulas (4)-(7), we obtain two formulas to calculate the cumulative precipitation over a period of time $(T)$ and/or within a certain region (region $S$ ). These are shown in formulas (8) (discretizing calculation for the cumulative precipitation over a period of time ( $T$ interval) and/or within a certain region (region $S)$ ).

Formulas (8) show that the cumulative precipitation calculated from the echo intensity integral method is larger than that calculated by the rainfall intensity integral method.

To analyze the characteristics of the difference $f\left(Z_{1}\right.$, $Z_{2}, Z_{3}, \ldots, Z_{n}$ ) between the two integration methods, we used three different functions to represent the variations of echo intensity. Specifically, the sinusoidal, linear, and the exponential functions are used to simulate echo intensity, and then the accumulative rainfalls for both stratiform and convective precipitation are calculated with these two methods

$$
\begin{aligned}
& \mathrm{EI}_{T}=\sqrt[b]{\frac{\int_{T} Z(t) d t}{a}} \approx \sqrt[b]{\frac{\sum_{T} Z(t) \cdot \Delta t}{a}} \\
& =\sqrt[b]{\frac{\left(Z_{1}+Z_{2}+Z_{3}+\cdots+Z_{n}\right)}{a}} \\
& =\sqrt[b]{\frac{Z_{1}}{a}}+\sqrt[b]{\frac{Z_{2}}{a}}+\sqrt[b]{\frac{Z_{3}}{a}}+\cdots+\sqrt[b]{\frac{Z_{n}}{a}} \\
& +f\left(Z_{1}, Z_{2}, Z_{3}, \ldots, Z_{n}\right), \\
& \mathrm{RI}_{T}=\int_{T} \sqrt[b]{\frac{Z(t)}{a}} d t \approx \sum_{T} \sqrt[b]{\frac{Z(t) \cdot \Delta t}{a}} \\
& =\sqrt[b]{\frac{Z_{1}}{a}}+\sqrt[b]{\frac{Z_{2}}{a}}+\sqrt[b]{\frac{Z_{3}}{a}}+\cdots+\sqrt[b]{\frac{Z_{n}}{a}}, \\
& \mathrm{EI}_{S}=\sqrt[b]{\frac{\int_{S} Z(x) d \mathrm{x}}{a}} \\
& \approx \sqrt[b]{\frac{Z_{1}}{a}}+\sqrt[b]{\frac{Z_{2}}{a}}+\sqrt[b]{\frac{Z_{3}}{a}}+\cdots+\sqrt[b]{\frac{Z_{n}}{a}} \\
& +f\left(Z_{1}, Z_{2}, Z_{3}, \ldots, Z_{n}\right),
\end{aligned}
$$




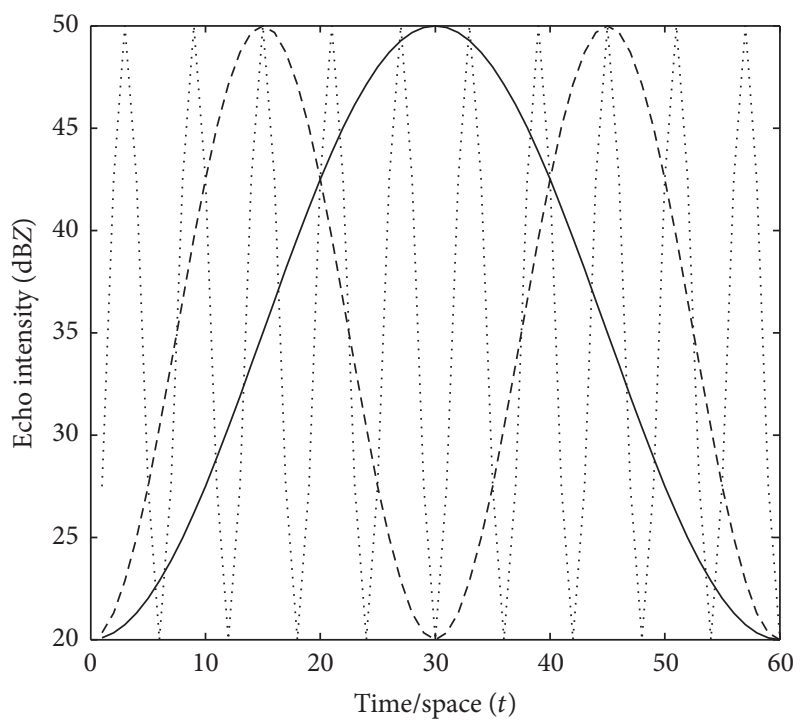

FIGURE 1: Variation of echo intensity with time/space (lines: $n=1$; dash line: $n=0.5$; dotted line: $n=0.1$ ).

$$
\begin{aligned}
\mathrm{RI}_{S} & =\int_{S} \sqrt[b]{\frac{Z(x)}{a}} d x \\
& \approx \sqrt[b]{\frac{Z_{1}}{a}}+\sqrt[b]{\frac{Z_{2}}{a}}+\sqrt[b]{\frac{Z_{3}}{a}}+\cdots+\sqrt[b]{\frac{Z_{n}}{a}}
\end{aligned}
$$

in which $f\left(Z_{1}, Z_{2}, Z_{3}, \ldots, Z_{n}\right)$ is a function of $Z$.

3.1. Sinusoidal Variation. To make accurate quantitative precipitation forecasts, the probability distribution of the precipitation must be considered. Previous studies have demonstrated that the summer rainfall in China generally exhibits a normal distribution [35-38]. In this section, the tempo$\mathrm{ral} / \mathrm{spatial}$ variation of the precipitation echo is represented by a sinusoidal function, and the echo intensity formula is as follows:

$$
\mathrm{dB} Z(t)=15 \sin \left(\frac{2 \pi}{60 n} \cdot t-\frac{\pi}{2}\right)+35,
$$

where $t$ represents the detection unit within a period/region (60 units in total); $n$ is a parameter used to control the speed of the sine wave; and its range is $0.02 \sim 2$. When $n$ is $0.1,0.5$, and 1 , the variations of the echo intensity with $t$ are shown in Figure 1. The figure shows that the curve is similar to the curve of normal distribution, and the variability of the echo intensity increased with a decreased $n$. The total amounts of reflectivity collected by each experiment with different frequency are almost 50\% of the rectangle area (outlined by maximum echo functions).

According to formula (9), if $n=2$, the echo intensity curve is exactly a half sine wave; if $n>2$, the curve is only a portion of a half sine wave; if $n$ is very large, the curve is similar to a linear signal. The variations of cumulative rainfall from the two integration methods are shown in Figure 2. The cumulative rainfall calculated using the echo intensity integral is always greater than that from the rainfall intensity integral. The changes of cumulative rainfall calculated from the two methods are consistent with the change of $n$. As illustrated in Figure 2, the cumulative stratiform rainfall (a) calculated by the echo intensity integral ranges from 17.5 to $20 \mathrm{~mm}$, and the cumulative rainfall calculated via rain intensity integral ranges from 13 to $15 \mathrm{~mm}$. For convective precipitation (b), the estimated cumulative rainfall from the echo intensity integral ranges from 19.8 to $22.5 \mathrm{~mm}$, and the cumulative rainfall calculated via rain intensity integral ranges from 15.5 to $18 \mathrm{~mm}$.

To compare the difference between the two integration methods, we used the normalized error, defined as RE (RE = $(\mathrm{RI}-\mathrm{EI}) /(\mathrm{RI}+\mathrm{EI}))$, to quantitatively represent the difference between the two integration methods. Figure 3 shows the variation of normalized error with $n$ for stratiform precipitation (a) and convective precipitation (b). The normalized error ranged from -0.138 to -0.5 and from -0.11 to -0.122 , respectively.

The above analysis shows that if echo intensity varies as a sinusoidal wave, the difference between the two methods is not obviously related to frequency. The normalized error exhibited a small fluctuation that was smaller for convective precipitation than for stratiform precipitation.

3.2. Linear Variation. If the temporal/spatial variation of the radar echo is simulated by a linear function, then the formula of the echo intensity is as follows:

$$
\mathrm{dB} Z(t)=\frac{m \cdot t}{60}+20
$$

In this formula, $t$ represents the detection unit (60 units total) within a period/region. The parameter $m$ controls the speed of the linear wave and it ranges from 0 to 30 . Given $m=30, m=20$, and $m=10$, the variation of the echo intensity with the time and space is shown in Figure 4 . The echo intensity increases with time, and the variation rate of the echo intensity increases with $m$.

The parameter $m$ indicates the variation rate of the input signal which reflects the stability of the precipitation process. A greater $m$ indicates a greater change of the echo intensity and a more unstable system. The variation of cumulative rainfall of these two integral methods with $m$ is shown in Figure 5. Similar to sinusoidal wave simulation, the accumulative rainfall from echo intensity integral is always greater than that from the rainfall intensity integral. With an increase of $m$, the linear amplification speed of echo intensity increases. As a result, the maximum value of the simulated echo also increases, which ultimately increases the total accumulated rainfall. According to Figure 5, (1) if $m=$ 0 , the simulated echo intensity is a constant $(20 \mathrm{dBZ})$, and the accumulated rainfall from two integration methods are the same; (2) if $m=30$, the echo intensity changes from $20 \mathrm{dBZ}$ to $50 \mathrm{dBZ}$, and the difference of the accumulated rainfall is greatest, which is $4.5 \mathrm{~mm}$ (stratiform) and $3.3 \mathrm{~mm}$ (convective), respectively.

Analysis of the variation of normalized error with $m$ for different precipitation types (Figure 6) shows that the normalized error always increases with $m$. For stratiform 


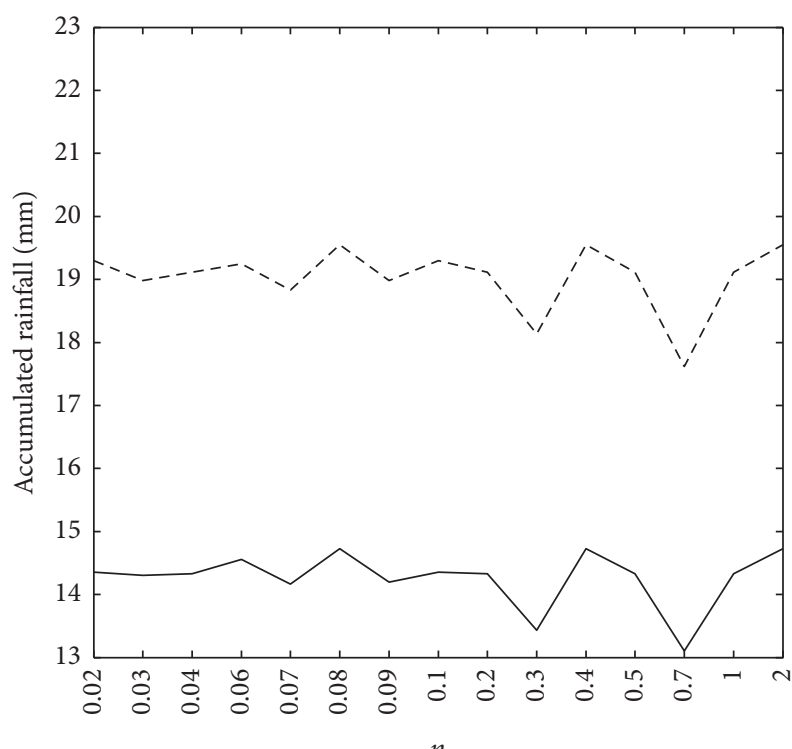

(a)

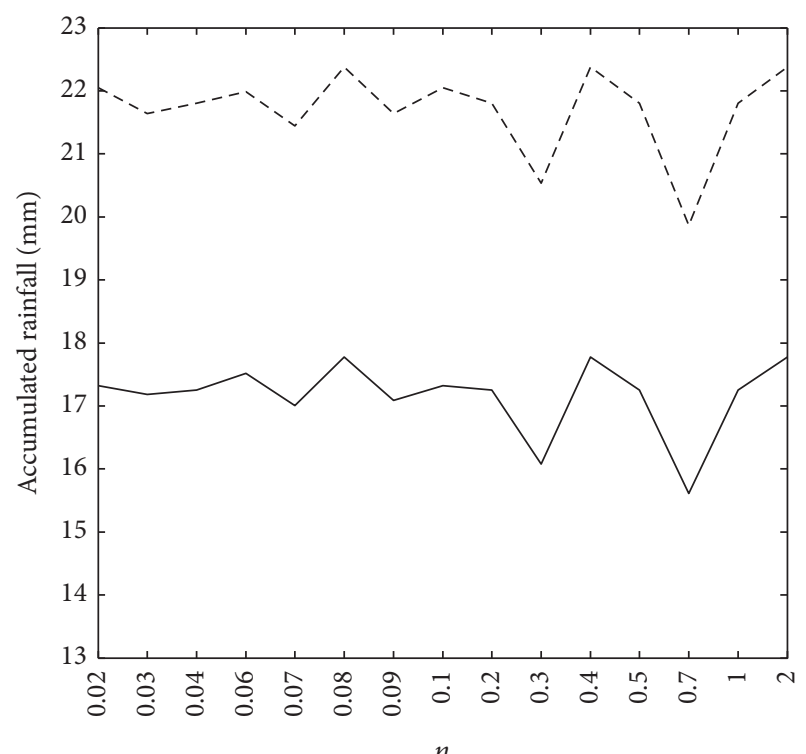

(b)

FIGURE 2: Variation of cumulative rainfall in two methods with the change of $n$ (lines: rain intensity integral; dash line: echo intensity integral; (a) $Z=200 I^{1.6}$; (b) $Z=300 I^{1.4}$, the same in the following figures).

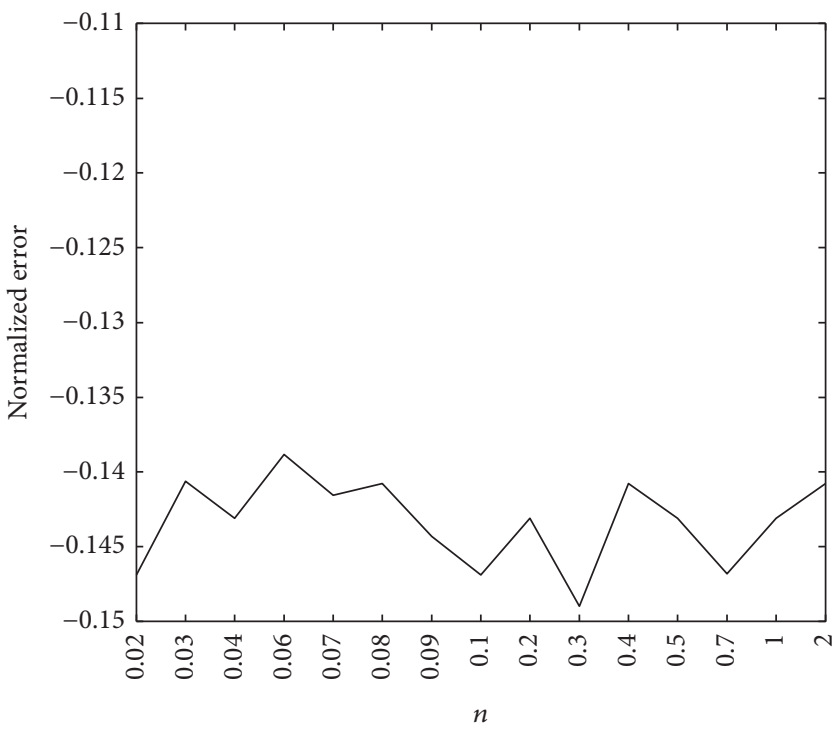

(a)

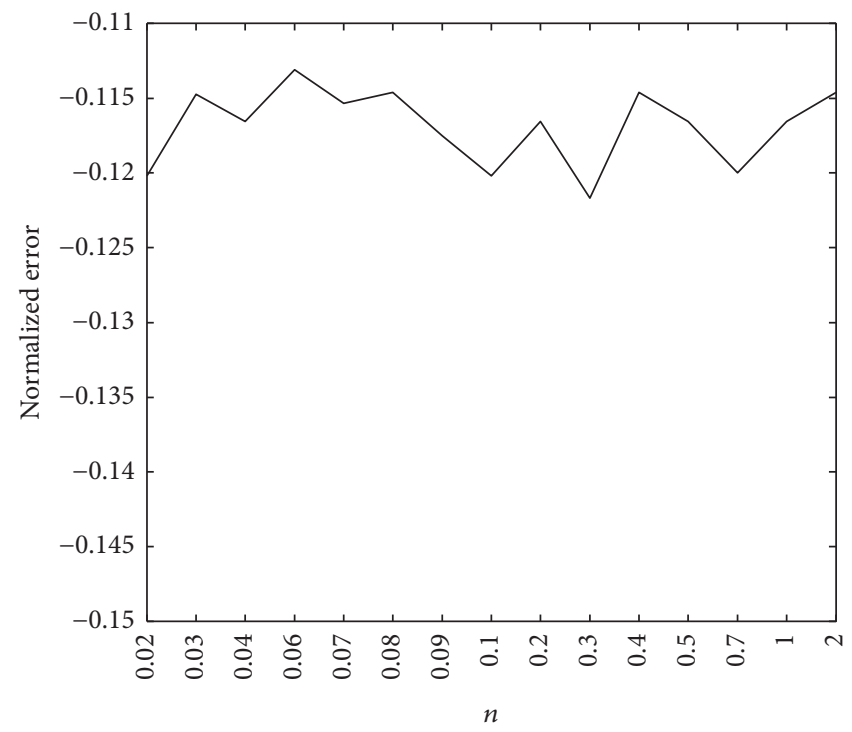

(b)

FIGURE 3: Variation of normalized error between the two cumulative methods with the change of $n$ ((a) $Z=200 I^{1.6}$; (b) $Z=300 I^{1.4}$, the same in the following figures).

precipitation, the normalized error ranges from 0 to -0.13 , and for convective precipitation, the normalized error ranges from 0 to -0.11 .

Therefore, if the echo intensity has linear variation, the normalized error between the two methods depends on the value of $m$. If $m$ increases, the normalized error of the two methods also increases. The normalized error of the cumulative rainfall between these two integration methods is relatively smaller for convective precipitation than the error for stratiform precipitation.
3.3. Exponential Variation. The temporal/spatial variation of the echo intensity is also simulated by the exponential function, and the formula is as follows:

$$
\mathrm{dBZ}(t)=30 \cdot\left(\frac{t}{60}\right)^{m}+20
$$

where $t$ represents the detection unit within a period and a region and there are 60 units in total. The parameter $m$ controls the speed of the exponential variation and it ranges 


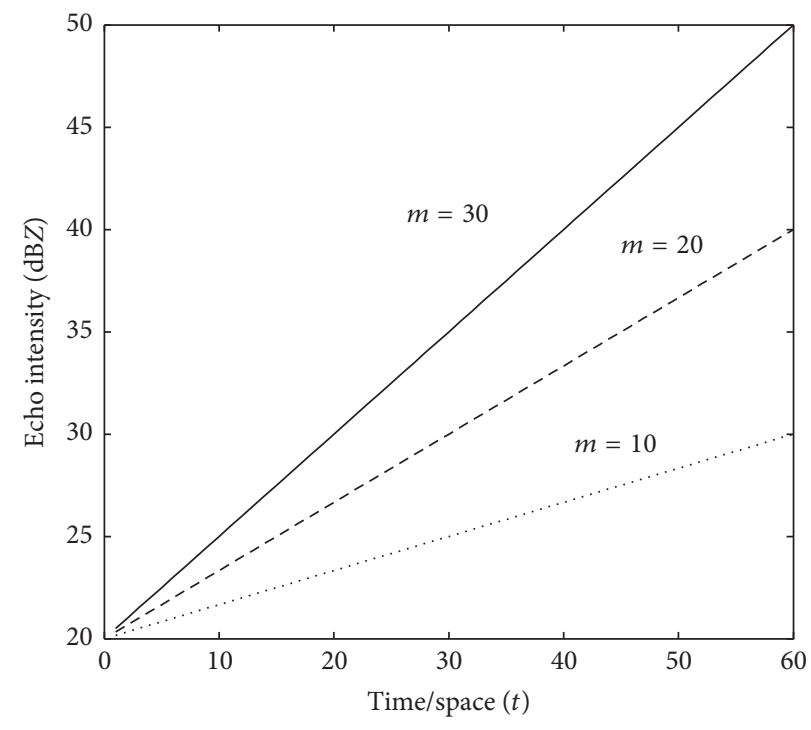

FIgURE 4: Variation of echo intensity with time/space.
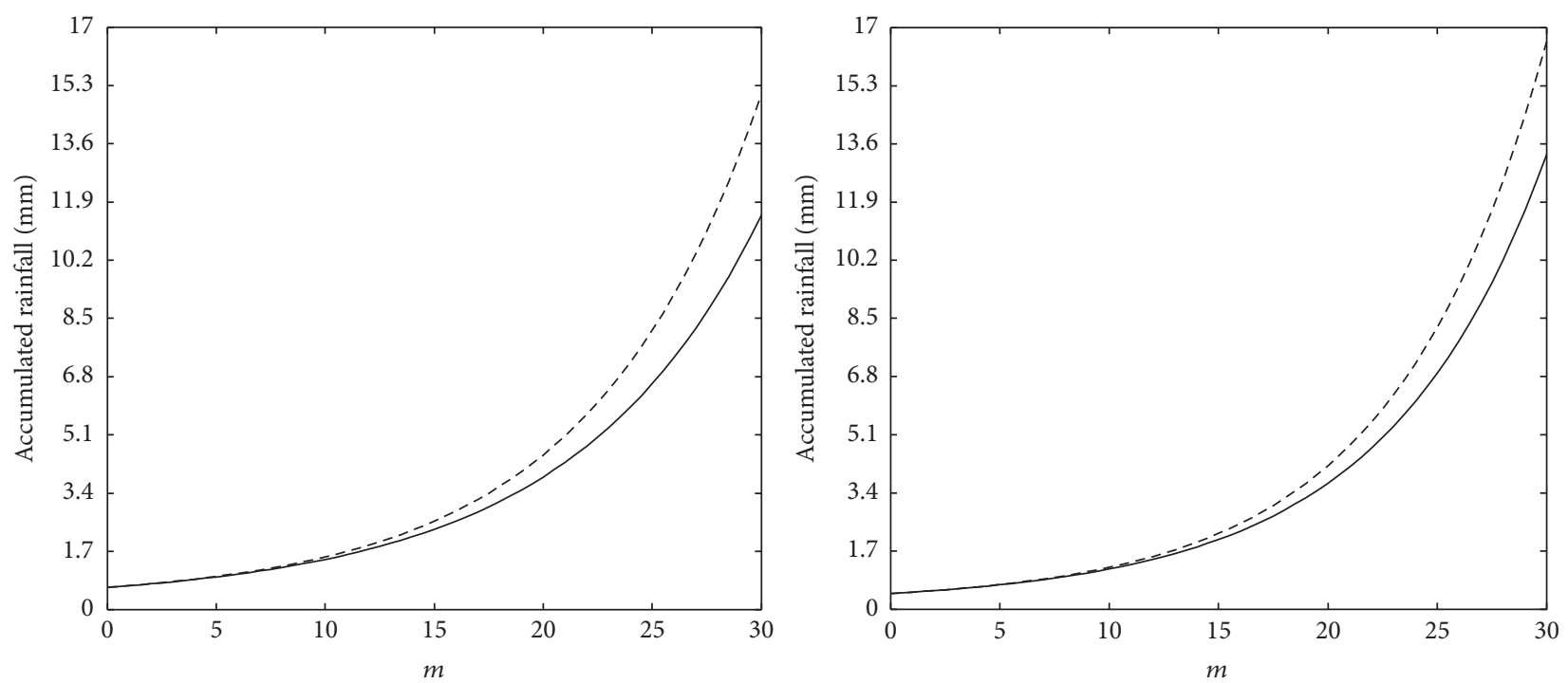

FIGURE 5: Variation of cumulative rainfall of two methods with the change of $m$.

from 0 to 10 . Given $m=0.1, m=1, m=2$, and $m=10$, the variation of the echo intensity with the time and space is shown in Figure 7. According to Figure 7, (1) if $m=0.1$, the change of echo intensity is initially rapid from 0 to $40 \mathrm{dBZ}$ and then decreases from 40 to $50 \mathrm{dBZ}$; (2) if $m=1$, the echo intensity curve is similar to linear simulation; (3) if $m=10$, the change of echo intensity is generally opposite to the case when $m=0.1$. It changes slowly in the beginning and then rapidly increases from 0 to $50 \mathrm{dBZ}$ after $t=40$.

Based on the characteristics of the exponential function, the variation of the echo intensity is not determined solely by $m$. According to formula (11) and Figure 7, it is clear that the echo intensity has abrupt changes. If there are fewer radar detection units, the abrupt changes occur when $m$ is small; if there are more radar detection units, the abrupt changes occur when $m$ is large.

The variations of cumulative rainfall with $m$ for these two methods are shown in Figure 8. The results from both methods show a similar trend which is an abrupt decrease for $0<m<1$ followed by a smooth gradual decrease after $m>1$. The accumulative rainfall from the echo intensity integral is greater than that from the rainfall intensity integral. For $m<1$, the change of the echo intensity is abrupt with the decrease of $m$. It increases from about 16 to more than $40 \mathrm{dBZ}$ in a short time at the beginning and sustains for a long time, resulting in stronger echo intensity and more estimated accumulative precipitation. For $m>1$, the abrupt increase of the echo intensity does not occur until after 

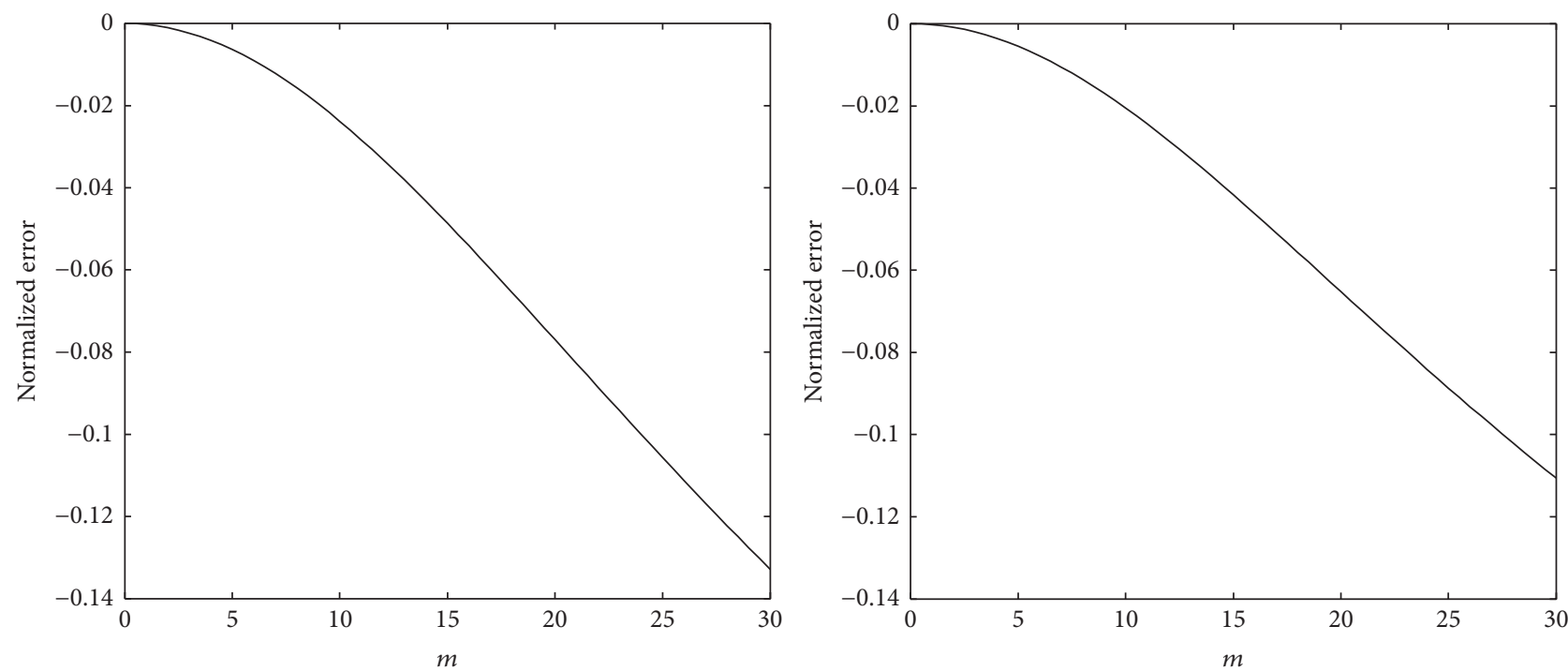

FIGURE 6: Variation of normalized error between two cumulative methods with the change of $m$.

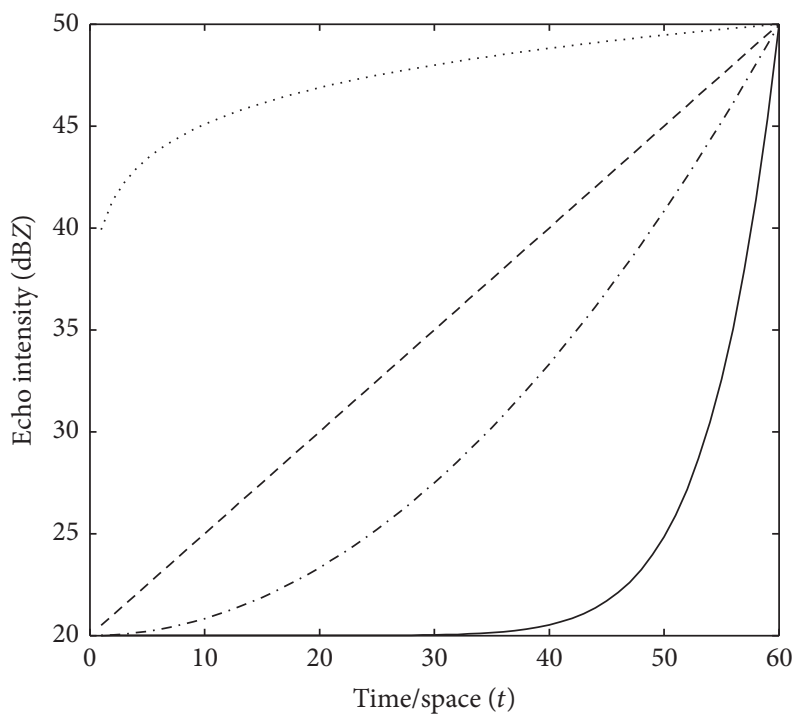

Figure 7: Variation of echo intensity with time/space (dotted line: $m=0.1$; dash line: $m=1$; dash dotted line: $m=2 ;$ lines: $m=10$ ).

a long interval with weak echo intensity, resulting in less estimated accumulative precipitation. As $m$ approaches 0 , the echo intensity rapidly increases to $50 \mathrm{dBZ}$, and the cumulative stratiform precipitation and convective precipitation values are $48.6 \mathrm{~mm}$ and $63.4 \mathrm{~mm}$, respectively (Figure 8). If $m$ is very large, the calculated cumulative rainfall is reduced and gradually decreases as $m$ decreases. As $m$ reaches infinity, the cumulative rainfall calculated by the echo intensity integral is $3.90 \mathrm{~mm}$ (stratiform) and $3.55 \mathrm{~mm}$ (convective), and the calculated accumulative rainfall from rainfall intensity integral is 1.45 (stratiform) and $1.50 \mathrm{~mm}$ (convective).

The variation of normalized error with $m$ (Figure 9) indicates that the differences range from 0 to -0.35 for stratiform precipitation and 0 to -0.30 for convective precipitation. As $m$ approaches infinity, the differences approach
-2.71 for stratiform precipitation and -2.29 for convective precipitation.

This analysis indicates that when the change of echo intensity is exponential, the normalized error between the two methods increases with $m$ and that the difference is smaller for convective precipitation than it is for stratiform precipitation.

\section{Analysis with Actual Radar Observation}

Based on the Z-I relation for stratiform precipitation, the cumulative precipitation for a $24 \mathrm{hr}$ period was calculated by both the echo intensity integral and the rainfall intensity integral. The radar observable data were taken from over the Huaihe River Basin on June 10, 2011. The ground station 

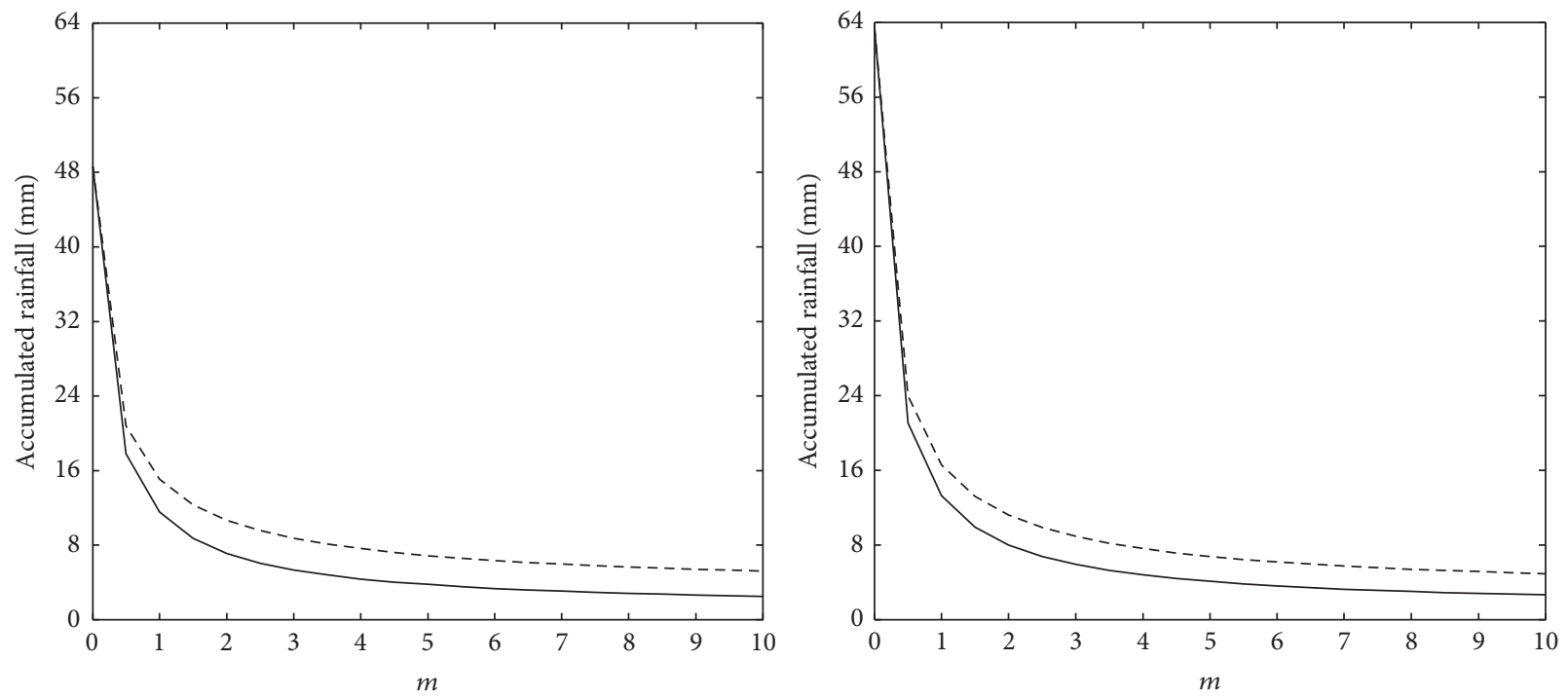

FIGURE 8: Variation of cumulative rainfall of two methods with the change of $m$.
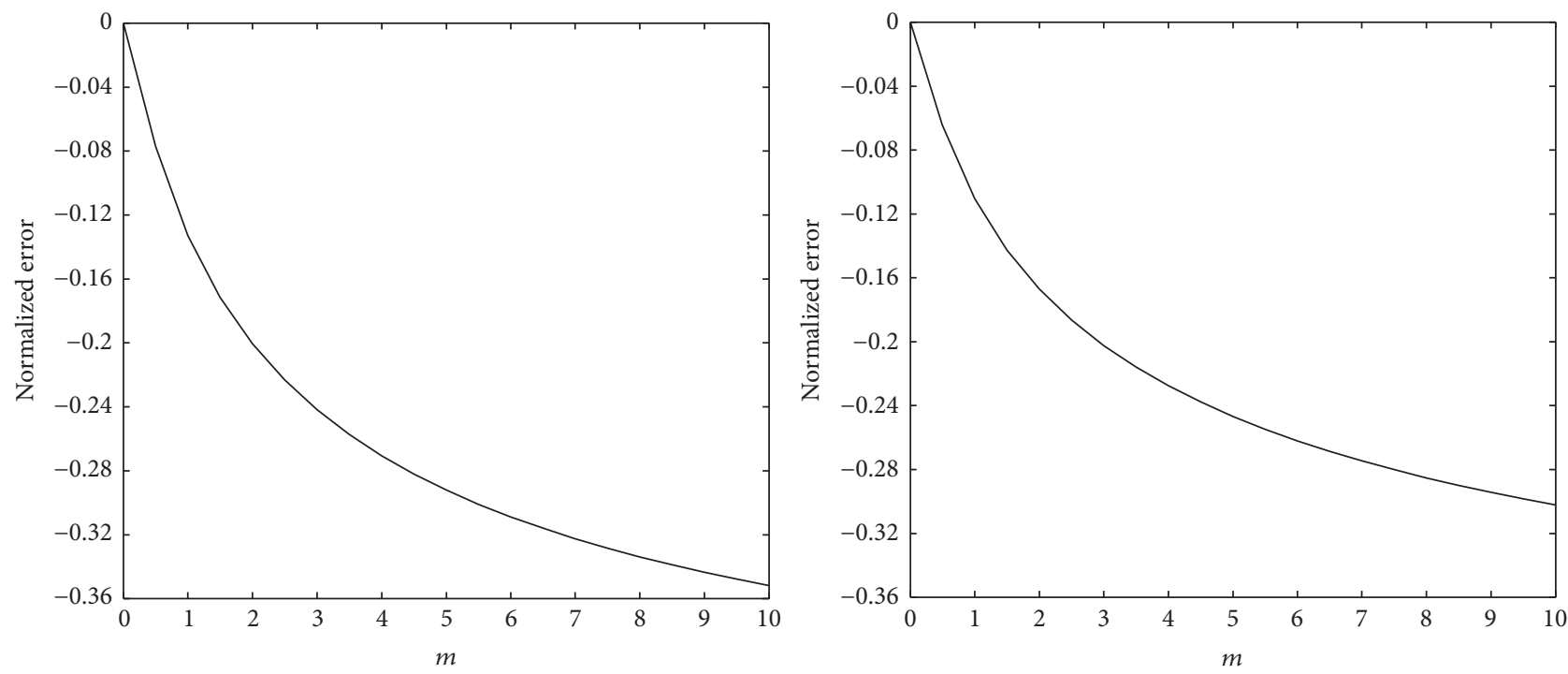

FIGURE 9: Variation of normalized error between the two cumulative methods with the change of $m$.

pluviometer data were from one hr of precipitation in the Huaihe River Basin on the same day. These data were used to verify the two integration schemes. The spatial distributions of the two integration schemes and the observation data are shown in Figures 10 and 11, respectively. Figure 10 shows that there are two high intensity zones (bottom and mid portions of Figure 10). In comparison with a topographic map, the large value areas lie between the mountains and the river. The larger value is between Dabie Mountain and the Yangtze River, and the other value is between Funiu Mountain and the Yellow River (which is within the range of radar detection in Zhumadian). Figure 11 shows that there is only one high intensity zone (bottom of Figure 11). A possible reason for this discrepancy is that there was a problem with the Zhumadian radar (a previous study found problems with the Zhumadian radar data).

The following is a statistical analysis of this case. The average accumulated rainfall calculated with the rainfall intensity integral and echo intensity integral was regarded as radar estimated rainfall. From the scatter density diagram of radar estimate precipitation (Figure 12(a)) and the difference between the two integration methods, it is clear that as the estimated rainfall increased, the difference between the two estimates increases. From the scatter density diagram of site observation (Figure 12(b)) and the difference between the two integration methods, we found that as observed rainfall increased, the difference between the two estimate approaches increases. The average difference between the 


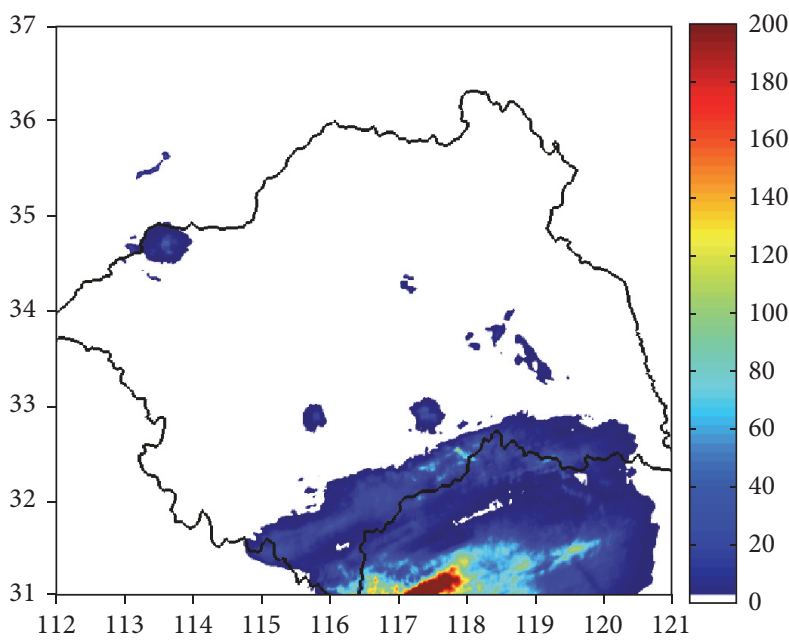

(a)

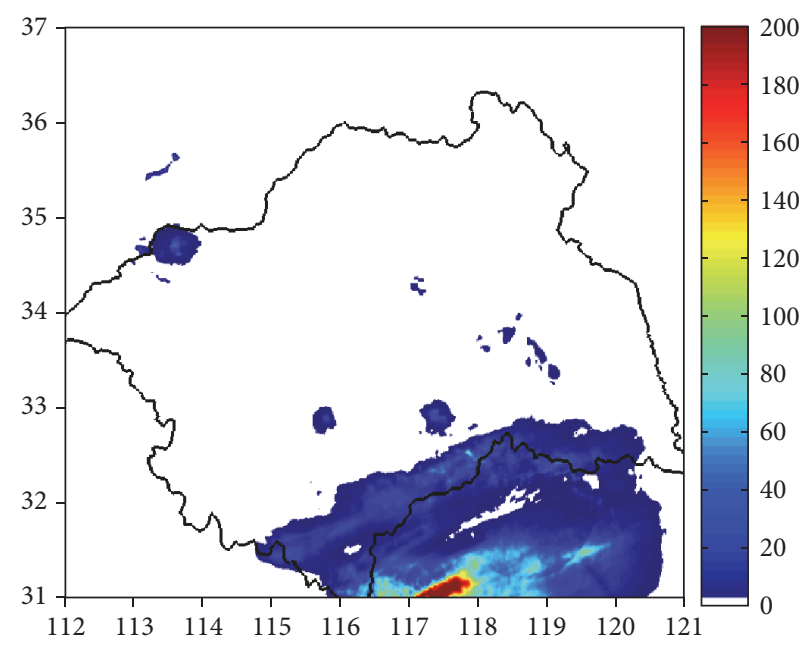

(b)

FIGURE 10: Spatial distribution of daily precipitation using echo intensity integral (a) and rainfall intensity integral (b).

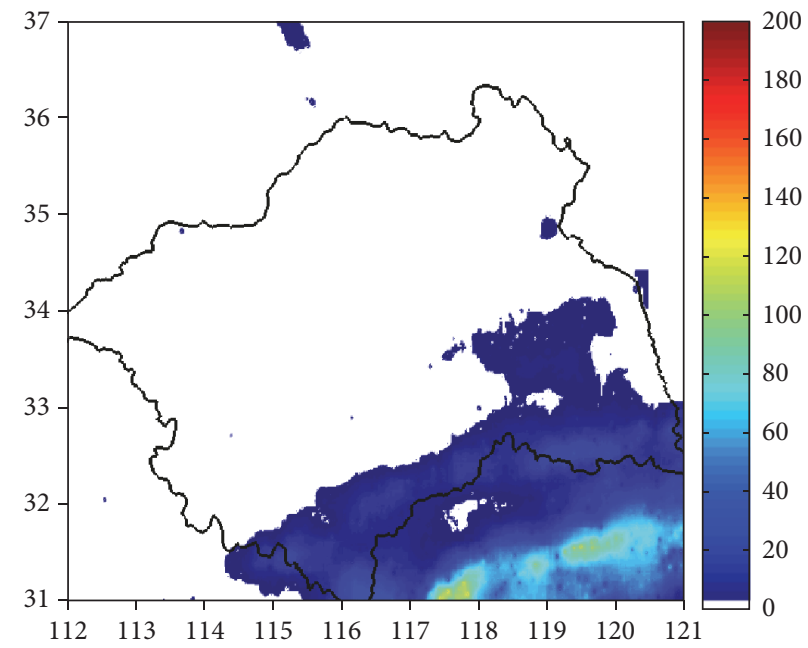

FIGURE 11: Spatial distribution of daily precipitation from site observation.

two methods was $3.367 \mathrm{~mm}$, and the standard deviation was $5.663 \mathrm{~mm}$.

\section{Conclusions}

The $Z$-I relation method is widely used for quantitative precipitation estimation based on weather radar data. It establishes a statistical relationship between the radar reflectivity and the precipitation intensity. We introduced two methods associated with the $Z-I$ relation approach to calculate cumulative precipitation. The results demonstrated that cumulative precipitation calculated from the echo intensity integration method was greater than that calculated by the rainfall intensity integration method. The normalized error of the calculated cumulative precipitation from these two methods depends on the variation of the echo intensity. The difference is small if the echo intensity changes slightly and gradually, but large if the echo intensity changes frequently (multiple peaks) and abruptly. When the echo intensity is simulated with a sinusoidal wave, the difference is larger than that simulated with a linear function. This is because the frequency of echo intensity can reach the maximum multiple times for a sinusoidal wave simulation, while it can only reach the maximum once for a linear signal simulation. If the echo intensity is an exponential signal, despite its single peak aspect, the difference can still be large due to abrupt change of the echo intensity.

When the echo intensity is simulated with a sinusoidal wave, the difference between the two methods is large, and the normalized error ranges from -0.15 to -0.138 and from -0.122 to -0.11 for two precipitation types. The variation of cumulative rainfall and normalized error with $n$ is always consistent.

When the echo intensity is simulated with a linear function, the normalized error increases with the parameter $m$. The normalized error ranges from 0 to -0.13 for stratiform precipitation and from 0 to -0.11 for convective precipitation. 


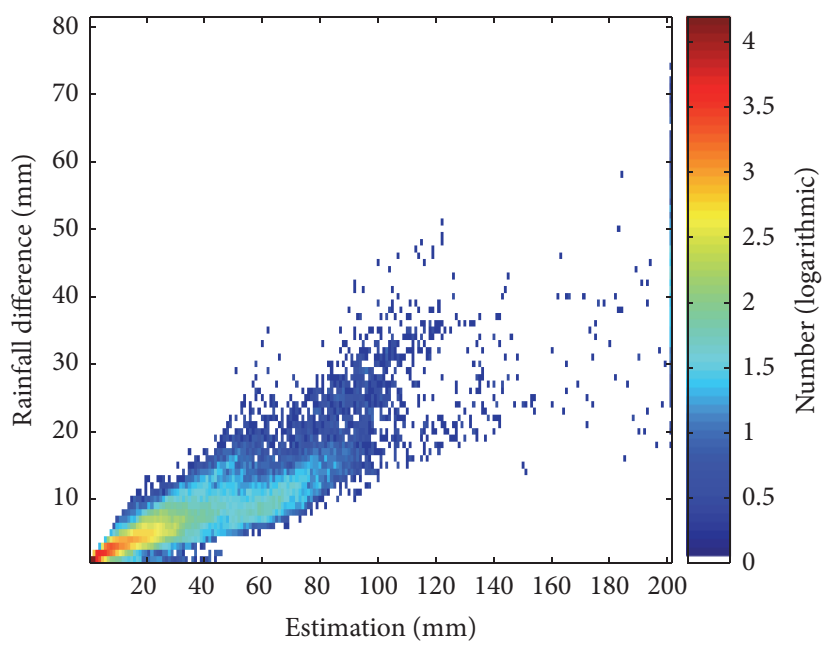

(a)

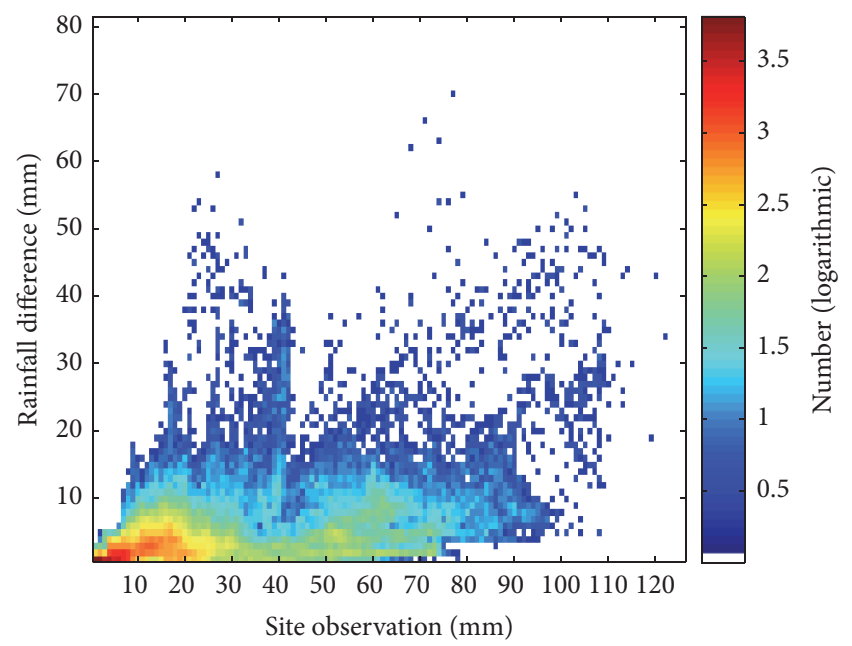

(b)

FIGURE 12: Scatter density diagrams of precipitation ((a) radar estimation; (b) site observation) and the difference between the two integration methods.

When the echo intensity was simulated with an exponential function, the normalized error first increased rapidly and then slowed down and stabilized. The normalized error ranged from 0 to -0.35 for stratiform precipitation and from 0 to -0.30 for convective precipitation.

When the two integration schemes with real radar were used to estimate cumulative precipitation for a day, their spatial distributions were similar.

He et al. (2004) showed that the Z-I relation method can underestimate the precipitation of heavy rainfall events [37]. Wang et al. (2008) found the Z-I relation method could overestimate the precipitation for weak rainfall events [38]. According to the simulation and observation data results, the cumulative precipitation from the echo intensity integral is greater than that from the rain intensity integral. The rain intensity integral usually underestimates the precipitation for heavy rainfall events, so application of the integral method of echo intensity can increase the estimated rainfall in the case of heavy precipitation and improve the estimate accuracy.

Time limit is a key issue discussed in this review. Based on the simulation results of the sinusoidal echo sequence, if the variation period of the radar echo intensity is more than one cycle, then the difference between the two kinds of cumulative rainfall appears to be irregular. The findings of this review are only relevant for rainfall accumulation within one change cycle of the precipitation system. The accumulated time should not exceed the life history of the precipitation system. For frequent summer precipitation events, the life histories of the systems are short and rainfall accumulates over several hours. For longer time scale systems, the precipitation is more stable and the life cycle may span several days.

\section{Conflicts of Interest}

The authors declare no conflicts of interest.

\section{Authors' Contributions}

The work presented here was carried out with collaboration among all the authors. Jing Ren, Yong Huang, Li Guan, and Jie Zhou defined the research theme. All authors carried out the simulations. This manuscript was finished by Jing Ren. Yong Huang and Li Guan checked the experimental results. All authors agreed to the manuscript being submitted.

\section{Acknowledgments}

This study was supported by the National Natural Science Foundation of China Grant no. 41275030, the R \& D Special Foundation for Public Welfare Industry (meteorology) of China under Grant no. GYHY201306040, the National Natural Science Foundation of Anhui Province under Grant no. 1508085MD64, the Public welfare Technology Application Research Plan of Anhui Province under Grant no. 1604f0804002, and Shanxi Meteorological Research Foundation under Grant no. SXKKFRY20100101. The authors acknowledge LetPub (www.letpub.com) for its linguistic assistance during the preparation of this manuscript.

\section{References}

[1] G. Wang, L. Liu, and Z. Ruan, "Application of doppler radar data to nowcasting of heavy rainfall," Journal of Applied Meteorological Science, vol. 18, no. 3, pp. 388-395, 2007.

[2] J. Pan and P. Zhang, "Estimating precipitation by radar measured vertical integration of liquid water," Journal of Nanjing Institute of Meteorology, vol. 23, no. 1, pp. 87-92, 2000.

[3] M. Smalley, T. L'Ecuyer, M. Lebsock, and J. Haynes, "A comparison of precipitation occurrence from the NCEP stage IV QPE product and the CloudSat cloud profiling radar," Journal of Hydrometeorology, vol. 15, no. 1, pp. 444-458, 2014.

[4] X.-Y. Liu, J.-T. Mao, J.-R. Li, and Y.-J. Zhu, "Application of radar-raingauge estimated mean area precipitation to runoff 
simulation," Journal of Hydraulic Engineering, vol. 22, no. 4, pp. 51-55, 2002.

[5] X. Liu, J. Mao, J. Li, and Y. Zhu, "Radar rainfall estimation and its application on runoff simulation over SHIGUANHE catchments," Acta Scientiarum Naturalium Universitatis Pekinensis, vol. 38, no. 3, pp. 342-349, 2002.

[6] K. Zhao, G. Liu, and W. Ge, "Precipitation calibration by using Kalman filter to determine the coefficients of the variational equation," Climatic and Environmental Research, vol. 6, no. 2, pp. 180-185, 2001.

[7] T. Zhou, B. Nijssen, G. J. Huffman, and D. P. Lettenmaier, "Evaluation of real-time satellite precipitation data for global drought monitoring," Journal of Hydrometeorology, vol. 15, no. 4, pp. 1651-1660, 2014.

[8] Z. Wang, X. Pei, J. Li, and L. Guan, "Application of principal characteristics extraction to consensus analysis of weather radar rainfall estimate," Inverse Problems, vol. 19, no. 3, pp. 525-531, 2003.

[9] L. Guan, Z. Wang, and X. Pei, "The consensus methods and effects of estimating rainfall using radar," Scientia Meteorologica Sinica, vol. 24, no. 1, pp. 104-111, 2004.

[10] J. S. Marshall, R. C. Langille, and W. M. Palmer, "Measurement of rainfall by radar," Journal of the Atmospheric Sciences, vol. 4, no. 4, pp. 186-192, 1947.

[11] H. R. Byers and P. R. Braham, "Thunderstorm structure and circulation," Journal of the Atmospheric Sciences, vol. 5, no. 3, pp. 71-86, 1948.

[12] E. A. Brandes, "Optimizing rainfall estimates with the aid of radar," Journal of Applied Meteorology, vol. 14, no. 7, pp. 13391345, 1975.

[13] C. G. Collier, P. R. Larke, and B. R. May, "A weather radar correction procedure for real-time estimation of surface rainfall," Quarterly Journal of the Royal Meteorological Society, vol. 109, no. 461, pp. 589-608, 1983.

[14] M. Kitchen, R. Brown, and A. G. Davies, "Real-time correction of weather radar data for the effects of bright band, range and orographic growth in widespread precipitation," Quarterly Journal of the Royal Meteorological Society, vol. 120, no. 519, pp. 1231-1254, 1994.

[15] C. Wu, Y. Wan, T. Wu, and H. Jin, "Vertical profile of radar echo and its determination methods," Journal of Applied Meteorological Science, vol. 17, no. 2, pp. 232-239, 2006.

[16] A. K. Mishra, R. M. Gairola, and V. K. Agarwal, "Rainfall estimation from combined observations using KALPANA-IR and TRMM- precipitation radar measurements over indian region," Journal of the Indian Society of Remote Sensing, vol. 40, no. 1, pp. 65-74, 2012.

[17] X. Li, Q. Zhang, and C.-Y. Xu, "Assessing the performance of satellite-based precipitation products and its dependence on topography over Poyang Lake basin," Theoretical and Applied Climatology, vol. 115, no. 3-4, pp. 713-729, 2014.

[18] F. Ouallouche and S. Ameur, "Rainfall detection over northern Algeria by combining MSG and TRMM data," Applied Water Science, vol. 6, no. 1, pp. 1-10, 2016.

[19] S. Jiang, L. Ren, Y. Hong et al., "Improvement of multi-satellite real-time precipitation products for ensemble streamflow simulation in a middle latitude basin in South China," Water Resources Management, vol. 28, no. 8, pp. 2259-2278, 2014.

[20] Y.-R. Lee, D.-B. Shin, J.-H. Kim, and H.-S. Park, "Precipitation estimation over radar gap areas based on satellite and adjacent radar observations," Atmospheric Measurement Techniques, vol. 8, no. 2, pp. 719-728, 2015.

[21] P. Nguyen, A. Thorstensen, S. Sorooshian, K. Hsu, and A. Aghakouchak, "Flood forecasting and inundation mapping using HiResFlood-UCI and near-real-time satellite precipitation data: the 2008 Iowa flood," Journal of Hydrometeorology, vol. 16, no. 3, pp. 1171-1183, 2015.

[22] A. Rafieeinasab, A. Norouzi, D.-J. Seo, and B. Nelson, "Improving high-resolution quantitative precipitation estimation via fusion of multiple radar-based precipitation products," Journal of Hydrology, vol. 531, no. 2, pp. 320-336, 2015.

[23] H. M. Grams, J. Zhang, and K. L. Elmore, "Automated identification of enhanced rainfall rates using the near-storm environment for radar precipitation estimates," Journal of Hydrometeorology, vol. 15, no. 3, pp. 1238-1254, 2014.

[24] P.-E. Kirstetter, J. J. Gourley, Y. Hong et al., "Probabilistic precipitation rate estimates with ground-based radar networks," Water Resources Research, vol. 51, no. 3, pp. 1422-1442, 2015.

[25] Y. Wen, P. Kirstetter, Y. Hong et al., "Evaluation of a method to enhance real-time, ground radar-based rainfall estimates using climatological profiles of reflectivity from space," Journal of Hydrometeorology, vol. 17, no. 3, pp. 761-775, 2016.

[26] X. Yang and L. Wei, "Radar rainfall estimation and its application in Haihe river basin," Haihe Water Resources, vol. 5, pp. 4650, 2013.

[27] Q. Wei, Z. Hu, L. Liu, and L. Wu, "C-band polarization radar data preprocessing and its application to rainfall estimation," Plateau Meteorology, vol. 35, no. 1, pp. 231-243, 2016.

[28] Y. Wu, L. Liu, Y. Zhou, J. Yang, and J. Zheng, "Study of raindrop influence of spectrum change on precipitation estimation," Plateau Meteorology, vol. 35, no. 1, pp. 220-230, 2016.

[29] B. Chen, W. Hu, and J. Pu, "Characteristics of the raindrop size distribution for freezing precipitation observed in southern China," Journal of Geophysical Research Atmospheres, vol. 116, no. 6, Article ID D06201, 2011.

[30] L. Zhou, J. Wang, D. Gong, H. Zhang, and R. Sheng, "A study on the distribution of raindrop size in three types of precipitation in Shandong province," Transactions of Atmospheric Sciences, vol. 35, no. 3, pp. 355-371, 2014.

[31] L. Jin, Q. Feng, J. Li, H. Sun, D. Shen, and X. Ren, "Application of automatic laser raindrops spectrometer in radar rainfall estimation," Climatic and Environmental Research, vol. 17, no. 6, pp. 740-746, 2012.

[32] E. A. Mueller and A. L. Sims, "Investigation of the quantitative determination of point and areal precipitation by radar echo measurements: final report," Ophthalmic Surgery Lasers and Imaging Retina, vol. 82, no. 9, pp. 567-573, 1963.

[33] H. P. Gerrish and H. W. Hiser, "Mesoscale studies of instability patterns and winds in the tropics," Miami Univ Fl Marine Lab. no. 82262, 1963.

[34] J. S. Marshall and K. Palmer, "The distribution of raindrops with size," Journal of the Atmospheric Sciences, vol. 5, no. 4, pp. 165$166,1948$.

[35] J. Cao and Y. Tao, "Does the rainfall in China fit the normal distribution?" Journal of Natural Disasters, vol. 11, no. 3, pp. 115$120,2002$.

[36] Y. Tao and X. Duan, "The research of normal distribution characteristics of the precipitation in Yunnan province," Scientia Meteorologica Sinica, vol. 23, no. 2, pp. 161-167, 2003. 
[37] Y. He, Y. Zhang, S. Liu, and S. Gu, "Evaluation of the precision of weather radar rainfall estimation algorithms," Journal of Nanjing Institute of Meteorology, vol. 27, no. 6, pp. 743-752, 2004.

[38] L. Wang, Y. Pei, and K. Meng, "Application of probabilityfitting technique in radar quantitative estimation precipitation," Meteorological and Environmental Sciences, vol. 31, supplement 1, pp. 195-199, 2008. 

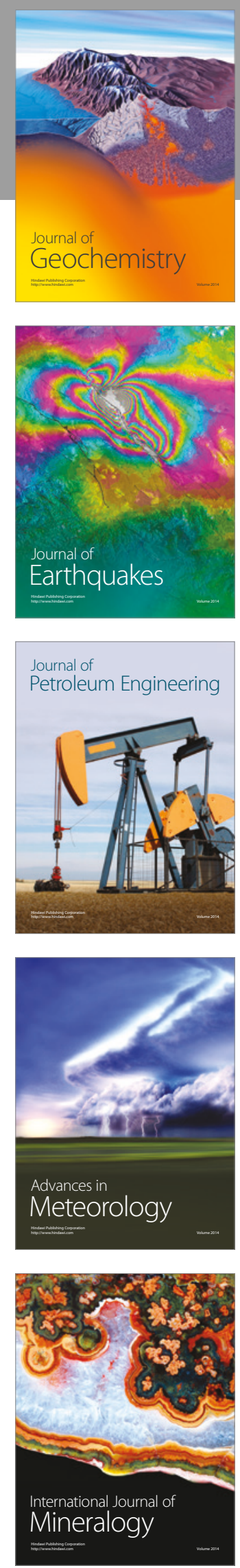
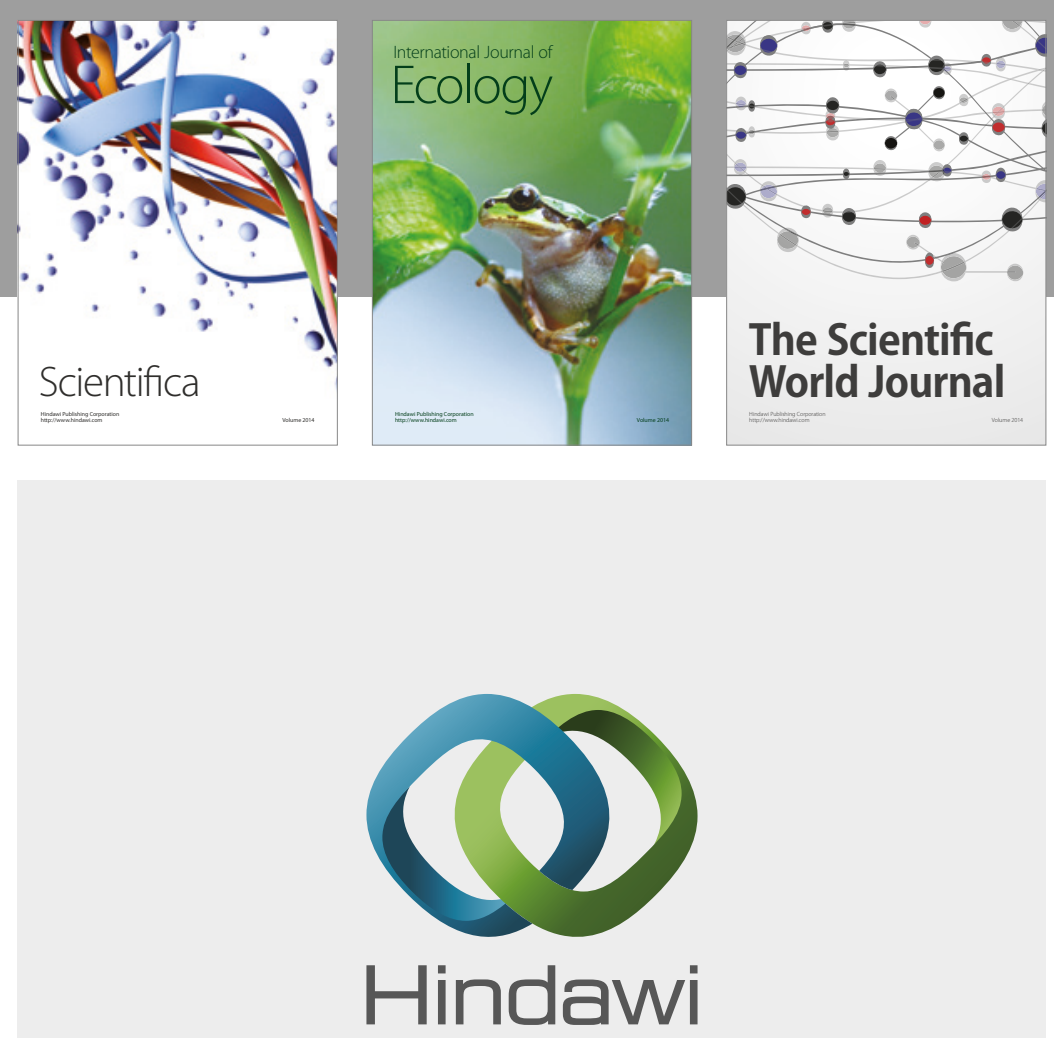

Submit your manuscripts at

https://www.hindawi.com
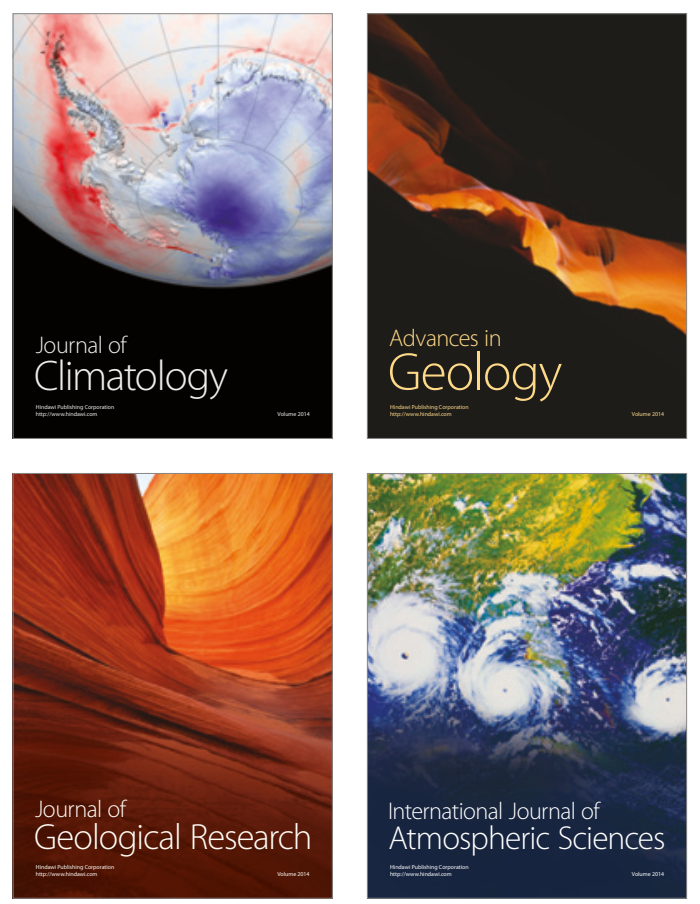

The Scientific

World Journal
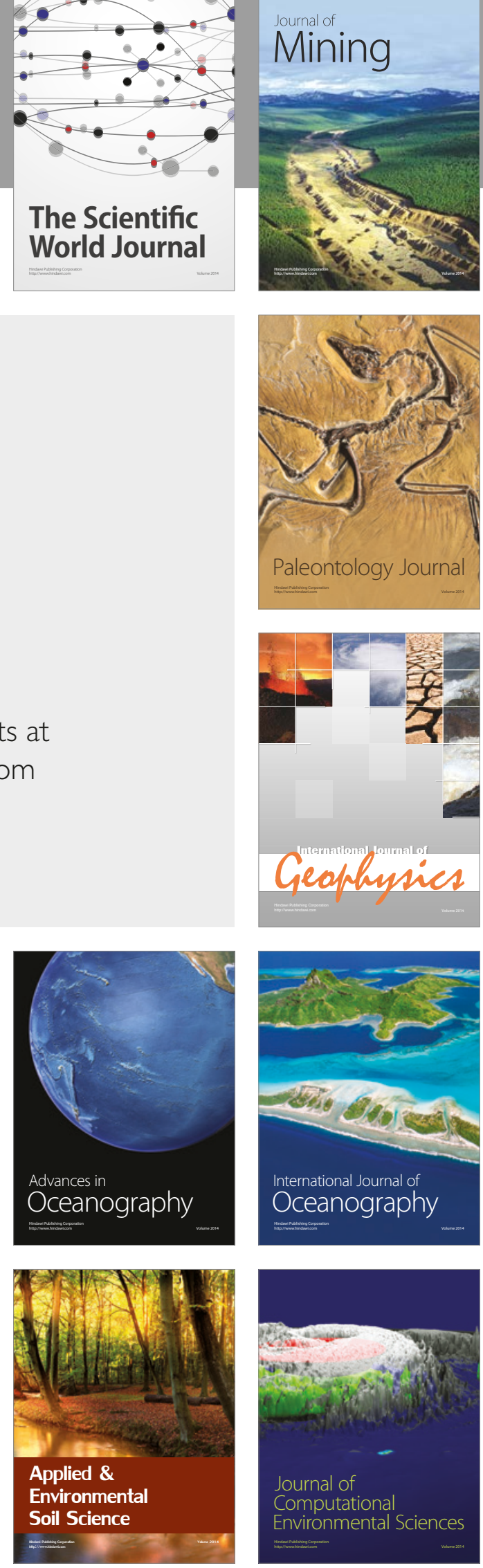